\title{
PHACE syndrome: clinical manifestations, diagnostic criteria, and management*
}

\author{
Anita Rotter ${ }^{1}$ \\ Maria Cecília Rivitti-Machado ${ }^{1}$ \\ Bernardo Gontijo ${ }^{2}$
}

\author{
Luciana Paula Samorano ${ }^{1}$ \\ Zilda Najjar Prado Oliveira ${ }^{1}$
}

DOI: http://dx.doi.org/10.1590/abd1806-4841.20187693

\begin{abstract}
Infantile hemangioma can be linked to other organ malformations. In 1996, PHACE syndrome was first defined as the association of large and segmental infantile hemangioma, usually on the face, head, or cervical region, with malformations of the posterior fossa of the brain, arterial anomalies of the central nervous system, coarctation of the aorta, cardiac defects, and ocular abnormalities. Over 300 cases of PHACE syndrome have been reported, and it is cconsidered one of the most common neurocutaneous vascular disorders in childhood. Knowledge of the features and locations of lesions that imply a greater risk of systemic involvement is crucial for the diagnosis and proper management of PHACE syndrome patients. This review highlights the diagnostic criteria for PHACE syndrome, the imaging workup for extracutaneous involvement, the treatment of infantile hemangioma, and the importance of a multidisciplinary approach in the management of these patients.
\end{abstract}

Keywords: Aortic coarctation; Hemangioma; Magnetic resonance imaging; Neurocutaneous syndromes; Propranolol; Stroke

\section{INTRODUCTION}

Infantile hemangioma $(\mathrm{IH})$ is the most frequent benign tumor in the pediatric population, with an incidence of $5 \%$ to $10 \%{ }^{1}$ These tumors usually do not present with systemic involvement. In cases of extensive and segmental $\mathrm{IH}$, especially on the face, scalp, and cervical region, a clinical and imaging workup is recommended to detect the changes that are described in PHACE syndrome. ${ }^{2}$

The most remarkable feature of PHACE syndrome is $\mathrm{IH}$, but abnormalities in the brain, aortic, thoracic, and cervical arteries, which are not obvious on clinical examination, have considerable potential for morbidity. ${ }^{3,4}$

\section{DEFINITION OF PHACE SYNDROME}

The first description of the association of PHACE syndrome with brain abnormalities was reported in 1978 by Pascual-Castroviejo. ${ }^{5}$ In 1996, Frieden et al. created the acronym PHACE (posterior fossa malformations, hemangioma, arterial anomalies, coarctation of the aorta/cardiac defects, and eye abnormalities) to detail the most represen- tative features of the syndrome. ${ }^{6}$ Subsequently, sternal malformations was added, giving rise to the acronym PHACES. ${ }^{7}$

In 2009, the diagnostic criteria for PHACE syndrome were established ${ }^{8}$ and then revised in 2016 by Garzon et al. ${ }^{3}$ It is a neurocutaneous condition in which extensive or segmental $\mathrm{IH}$, usually on the face, scalp, or cervical region, can be associated with posterior fossa malformations, arterial abnormalities [primarily in the central nervous system (CNS)], coarctation of the aorta, cardiac defects, and ocular abnormalities. ${ }^{6}$

\section{PREVALENCE}

PHACE syndrome is observed in $2 \%$ to $3 \%$ of $\mathrm{IH}$ cases. There are over 300 cases in the literature, and it is considered one of the most frequent neurocutaneous vascular disorders in childhood. According to several studies, when the IH develops on the face and is segmental or large, the likelihood of it being associated with PHACE syndrome is $20 \%$ to $31 \%$. PHACE syndrome affects

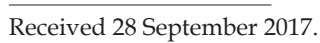

Accepted 07 January 2018

* Work conducted at the Dermatology Department. Hospital das Clínicas, Faculdade de Medicina da Universidade de São Paulo (HC-FMUSP), São Paulo, Brazil; and Dermatology Unit. Hospital das Clínicas, Universidade Federal de Minas Gerais (UFMG), Belo Horizonte (MG), Brazil.

Financial support: None.

Conflict of interest: None.

Dermatology Department, Hospital das Clínicas, Faculdade de Medicina da Universidade de São Paulo (HC-FMUSP), São Paulo, Brazil

Dermatology Unit. Hospital das Clínicas, Universidade Federal de Minas Gerais (UFMG), Belo Horizonte (MG), Brazil.

MAILING ADDRESS:

Anita Rotter

Email: anita.rotter@gmail.com

(C)2018 by Anais Brasileiros de Dermatologia 
females more frequently (9:1). Infantile hemangioma (most cases), cerebrovascular (83\% to $91 \%$ ) and cardiac ( $41 \%$ to $67 \%$ ) changes are among its most common manifestations. ${ }^{2,9,10}$

\section{PATHOGENESIS}

The pathogenesis of PHACE syndrome is unknown. It has been postulated to result from defective embryogenesis between weeks 3 and 12 of gestation, before or during vasculogenesis, because certain malformations and $\mathrm{IH}$ can affect the same side of the body. ${ }^{11}$

There is no evidence of genetic abnormalities that contribute to the development of PHACE syndrome. ${ }^{12}$

\section{DIAGNOSTIC CRITERIA}

In 2009, a group of various specialties (dermatology, neurology, oncology, genetics, cardiology, and ophthalmology) established criteria for the diagnosis of PHACE syndrome, stratifying it into 2 categories:

1. PHACE syndrome, defined by the presence of segmental $\mathrm{IH}$ larger than $5 \mathrm{~cm}$ on the face, scalp, or cervical region, associated with 1 major criterion or 2 minor criteria.

2. Possible PHACE syndrome, defined by the presence of $\mathrm{IH}$ and 1 minor criterion.

Major and minor criteria have been determined, based on the vascular and structural involvement of the brain, cardiovascular system, eye, and midline (Chart 1$){ }^{8}$

In 2016, new recommendations for the diagnosis and follow-up of patients with PHACE syndrome were published by a multidisciplinary group, comprising neuroradiology, neurosurgery, neurology, cardiology, cardiothoracic surgery, dermatology, otorhinolaryngology, hematology-oncology, and plastic surgery. In addition to medical experience and a literature review of the extracutaneous involvement, prevalence, progression and morbidity of PHACE syndrome, follow-up and family care were included. ${ }^{3}$

\section{CUTANEOUS INVOLVEMENT}

At birth, IH can be absent or present as a precursor lesion that is represented by a pale or slightly erythematous or telangiectatic area. However, nearly all IHs are already visible at the end of the first month of life. Regarding its progression, 3 phases have been described: proliferation (with increased growth in the first 5 months of life), stabilization, and spontaneous involution (lasting for years).$^{10,13}$

IHs that are associated with PHACE syndrome tend to be large $(>5 \mathrm{~cm}$ in diameter) or segmental - a term that has been proposed to describe the morphology of the hemangioma that affects one region and does not arise from a focal point. These IHs can present as telangiectasias, solitary lesions, confluent plaques, small papules that assume a specific distribution, and tumors with deeper involvement. ${ }^{14}$ Haggstrom et al. suspected a relationship between the facial location and extracutaneous involvement of an $\mathrm{IH} .{ }^{9}$ Hence, the face was divided into 4 segments that are not related to the dermatomes or Blaschko lines but to the prominences of facial development: frontotemporal, frontonasal, maxillary, and mandibular. IHs on the frontotemporal and frontonasal segments bear a higher risk of ocular and CNS involvement, whereas those on the mandibular segment are linked to a greater risk of midline and cardiovascular defects (Figures 1 to 4 ). ${ }^{11}$

\section{CHART 1: Diagnostic criteria for PHACES syndrome}

\begin{tabular}{|c|c|c|}
\hline System & Major criteria & Minor criteria \\
\hline \multirow[t]{6}{*}{$\begin{array}{l}\text { Brain } \\
\text { (vascular) }\end{array}$} & $\begin{array}{l}\text { Anomalies of larger } \\
\text { brain vessels }\end{array}$ & $\begin{array}{l}\text { Persistence of em- } \\
\text { bryonic arteries }\end{array}$ \\
\hline & $\begin{array}{l}\text { Arterial dysplasia, } \\
\text { stenosis or occlusion }\end{array}$ & $\begin{array}{l}\text { Proatlantal in- } \\
\text { tersegmental artery }\end{array}$ \\
\hline & $\begin{array}{l}\text { Absence or hypo- } \\
\text { plasia }\end{array}$ & $\begin{array}{l}\text { Primitive hypo- } \\
\text { glossal artery }\end{array}$ \\
\hline & $\begin{array}{l}\text { Aberrant origin or } \\
\text { course }\end{array}$ & $\begin{array}{l}\text { Primitive ophthal- } \\
\text { mic artery }\end{array}$ \\
\hline & $\begin{array}{l}\text { Persistence of trigem- } \\
\text { inal artery }\end{array}$ & \\
\hline & Saccular aneurysms & \\
\hline \multirow[t]{3}{*}{$\begin{array}{l}\text { Brain } \\
\text { (structural) }\end{array}$} & $\begin{array}{l}\text { Posterior fossa } \\
\text { anomaly }\end{array}$ & $\begin{array}{l}\text { Extra-axial lesion } \\
\text { compatible with } \\
\text { intracranial he- } \\
\text { mangioma }\end{array}$ \\
\hline & Dandy-Walker & \\
\hline & $\begin{array}{l}\text { Unilateral/bilateral } \\
\text { hypoplasia/dyspla- } \\
\text { sia of the cerebellum }\end{array}$ & \\
\hline \multirow[t]{4}{*}{ Cardiovascular } & Aortic arch anomaly & $\begin{array}{l}\text { Defect of the ven- } \\
\text { tricular septum }\end{array}$ \\
\hline & $\begin{array}{l}\text { Coarctation of the } \\
\text { aorta }\end{array}$ & $\begin{array}{l}\text { Right-sided aortic } \\
\text { arch (double aortic } \\
\text { arch) }\end{array}$ \\
\hline & Aneurysm & \\
\hline & $\begin{array}{l}\text { Aberrant origin of } \\
\text { subclavian artery } \\
\text { with or without } \\
\text { vascular ring }\end{array}$ & \\
\hline \multirow[t]{7}{*}{ Ocular } & $\begin{array}{l}\text { Posterior segment } \\
\text { anomalies }\end{array}$ & $\begin{array}{l}\text { Anterior segment } \\
\text { changes }\end{array}$ \\
\hline & $\begin{array}{l}\text { Persistence of fetal } \\
\text { vascularization }\end{array}$ & Sclerocornea \\
\hline & $\begin{array}{l}\text { Vascular anomalies } \\
\text { of the retina }\end{array}$ & Cataracts \\
\hline & $\begin{array}{l}\text { Optic disc anomalies, } \\
\text { morning glory-type }\end{array}$ & Coloboma \\
\hline & $\begin{array}{l}\text { Optic nerve hypo- } \\
\text { plasia }\end{array}$ & Microphthalmia \\
\hline & Coloboma & \\
\hline & $\begin{array}{l}\text { Peripapillary staphy- } \\
\text { loma }\end{array}$ & \\
\hline \multirow[t]{4}{*}{ Midline } & Sternal deformities & Hypopituitarism \\
\hline & Sternal cleft & Ectopic thyroid \\
\hline & Supraumbilical raphe & \\
\hline & Sternal defects & \\
\hline
\end{tabular}

Source: Adapted from Metry D et al., 2009.8 


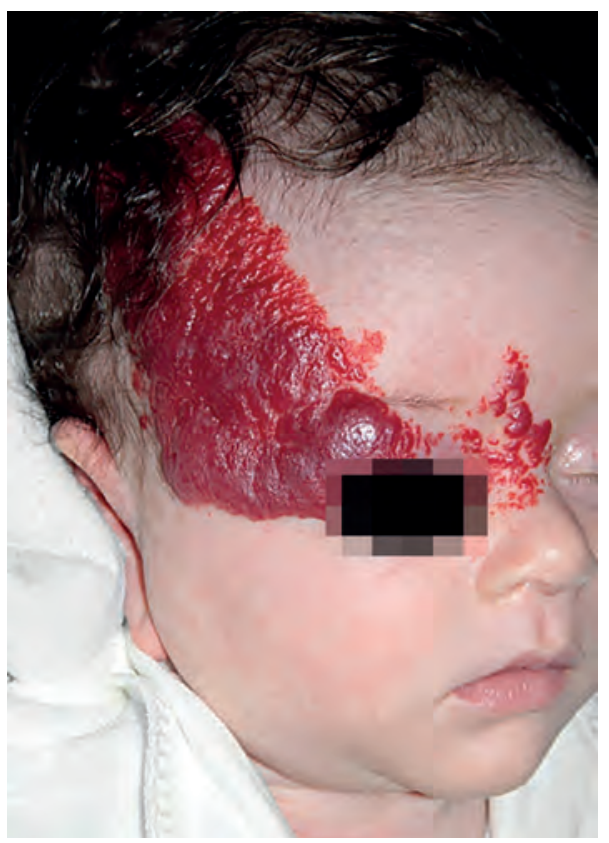

FigURE 1: Infantile hemangioma on the frontotemporal segment

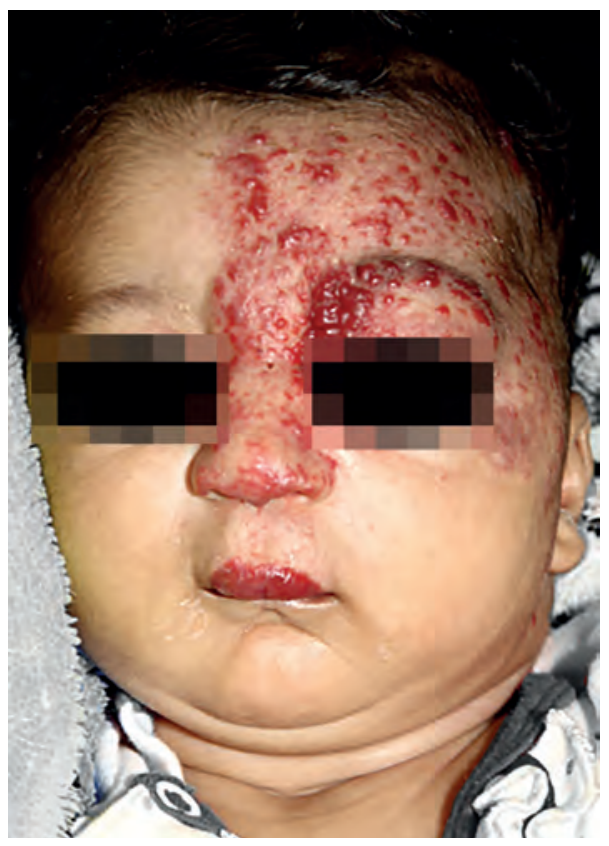

FIGURE 2: Infantile hemangioma on the frontonasal and frontotemporal segments

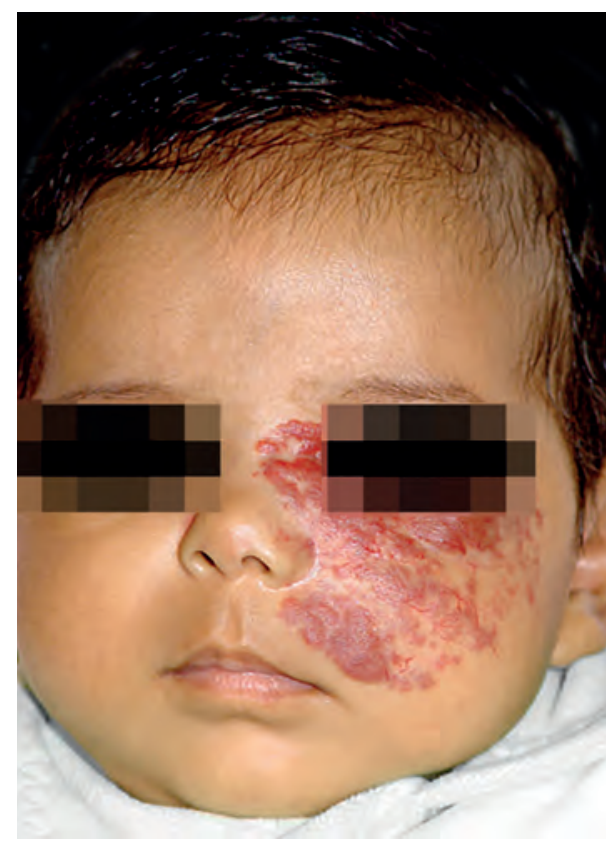

Figure 3: Infantile hemangioma on the maxillary segment

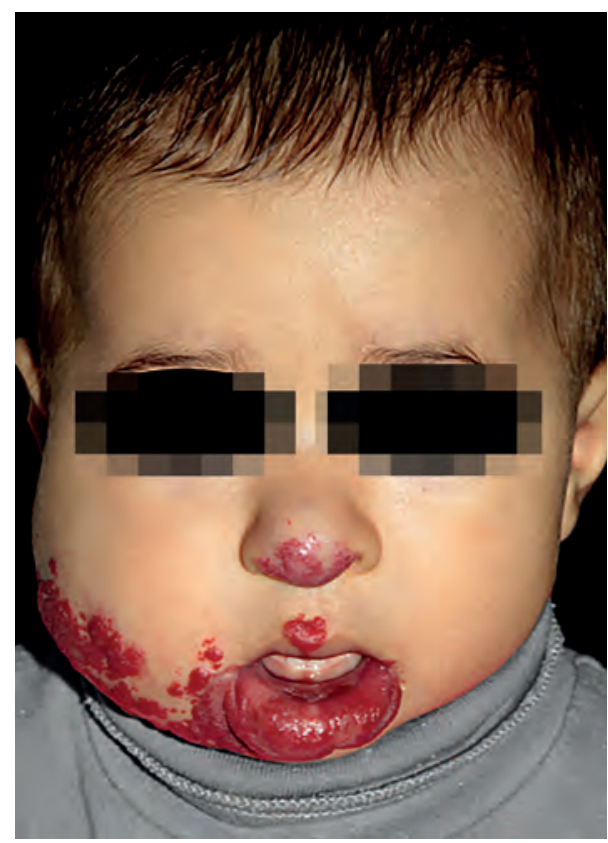

FigURE 4: Infantile hemangioma on the mandibular segment
Approximately $90 \%$ of the hemangiomas in PHACE syndrome are located on the cephalic segment. The face is the most commonly affected site, but lesions can develop on the scalp and postauricular and cervical regions. Large and segmental IHs on the occipital, upper thoracic, trunk, and proximal upper limb regions have also been described in PHACE syndrome. ${ }^{15}$

Large IHs on the infraorbital region that cause proptosis can be associated with the typical arterial anomalies in PHACE syndrome (Figure 5). ${ }^{16}$ Further, in the definition of possible PHACE syndrome, a small, nonsegmental IH or even the absence of cutaneous hemangiomas can be observed. $7,17,18$

\section{VASCULAR AND STRUCTURAL INVOLVEMENT OF THE BRAIN}

Cerebrovascular changes in PHACE syndrome increase the risk for a cerebrovascular accident (CVA). Although it is rare, its incidence peaks when - in addition to CNS changes - there are cardiac malformations, such as coarctation of the aorta. ${ }^{19}$

Cerebrovascular accidents in the pediatric population have a multifactorial etiology, and patients with PHACE syndrome have several risk factors, such as possible vascular stenosis and occlusion, with the subsequent reduction in blood flow and thromboembolism, related to potential cardiac and supraaortic arterial lesions. ${ }^{3}$

In 2013, Metry et al. described the changes that were seen on brain magnetic resonance angiography (MRA) that predicted the 

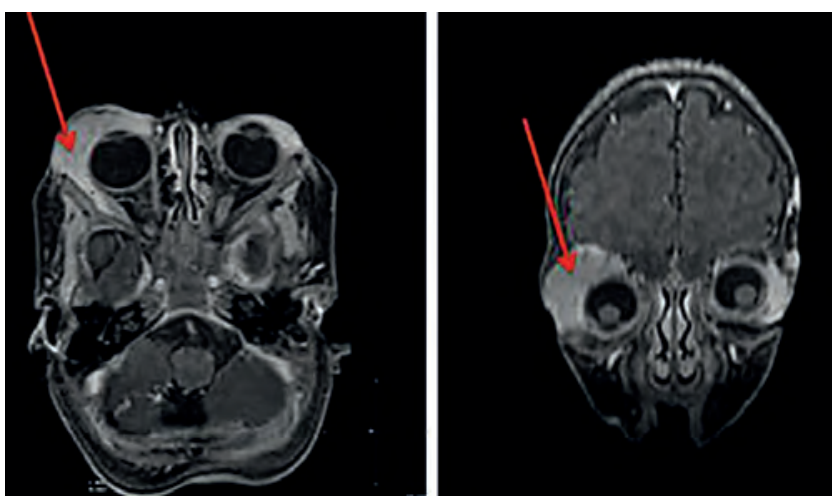

FIGURE 5: Brain MRI with a hemangioma on the right periorbital region

risk of CVA. These alterations included a severe narrowing or lack of visualization of the principal cerebral and cervical arteries, associated with insufficient collateral circulation. Chart 2 lists the main cerebrovascular changes that occur in patients with PHACE and stratifies the risk of CVA development into high and standard. Even cases that are classified as standard are at risk of a brain lesion due to hypoperfusion. Further, in cases in which the MRA shows severe vascular changes, the presence of collateral flow must be studied more extensively with a test that details perfusion. ${ }^{20}$

In 2010, Hess et al. described the main magnetic resonance imaging (MRI) and computed tomography angiography findings in 70 children with PHACE syndrome and arteriopathy. Dysgenesis was the most common malformation, followed by an abnormal vascular origin and course of the cervical and cerebral arteries and a narrowing and lack of visualization of the affected vessel. ${ }^{2}$

In 2012, Siegel et al. registered 22 cases of PHACE syndrome and ischemic cerebrovascular accident (iCVA). By MRI, there was a lack of visualization or narrowing of at least 1 principal cerebral vessel in 19 of 22 cases. In 15 cases, more than 2 vessels were affected, and in 13 patients, there was associated aortic arch malformation. ${ }^{19}$

Based on the brain MRA findings, the risk of CVA in patients with PHACE syndrome can be classified as low, intermediate, and high. ${ }^{3}$ The low-risk findings include frequently detected changes in the population, with minimal or no clinical impact, such as persistence of the embryonic artery; an abnormal arterial origin or course; and variations in the circle of Willis, which are insignificant with regard to hemodynamics.

The intermediate risk group comprises patients with nonstenotic dysgenesis and narrowing or occlusion of the arteries of the Circle of Willis or located in its vicinity, with no effects on hemodynamics.

The patients in the high-risk group show significant narrowing or occlusion of cerebral vessels that are close to or are part of the Circle of Willis, resulting in isolated circulation; multiple stenoses that are associated with complex blood flow, potentially interfering with brain perfusion; and findings in the brain parenchyma that suggest chronic and silent ischemia. Patients with cerebrovascular stenosis and coarctation of the aorta are also considered to be at high risk for neurological ischemic events (Figure 6).
CHART 2: Risk stratification for cerebrovascular accidents according to brain magnetic resonance angiography findings

$\begin{array}{ll}\text { Risk } & \text { Cerebrovascular changes } \\ \text { High } & \begin{array}{l}\text { Severe narrowing or stenosis by }>75 \% \text { or } \\ \text { lack of visualization of a main vessel (in- } \\ \text { ternal carotid, middle/anterior/posterior } \\ \text { cerebral, basilar, and vertebral artery), with } \\ \text { no evidence of collateral circulation }\end{array} \\ & \begin{array}{l}\text { Narrowing or stenosis by }<75 \% \text { or lack of } \\ \text { visualization of a main vessel with collater- } \\ \text { Standard }\end{array} \\ & \begin{array}{l}\text { Narrowing or stenosis by }<75 \% \text { of a main } \\ \text { vessel. }\end{array} \\ & \begin{array}{l}\text { Hypoplasia, dysplasia, aberrant origin and } \\ \text { course of main vessels. Aberrant subclavi- } \\ \text { an artery. Persistence of embryonic arteries. }\end{array}\end{array}$

Source: Adapted from Metry D et al., 2013. ${ }^{20}$

Structural brain changes occur in $30 \%$ to $80 \%$ of patients with PHACE syndrome (Figure 7). When the lesions are unilateral, the vascular changes and cutaneous IH tend to be on the same side. In most cases, the cerebral lesions do not progress, but the associated signs and symptoms of neuropsychomotor developmental delay, seizures, and headaches should be monitored. Pituitary structural abnormalities or symptoms that are suggestive of endocrine diseases should be examined in these cases. ${ }^{21}$

Because structural and vascular brain changes can lead to neurological sequelae, such as seizures and developmental delays, Tangtiphaiboontana et al. followed the neurological development of 29 children with PHACE syndrome aged over 1 year. In 20 children, delays in speech and changes in gross motor development were seen. ${ }^{22}$

However, there are few studies on the morbidity and neurological outcome in these patients. Neurological follow-up is important in determining the prognosis and appropriate therapeutic intervention. ${ }^{23}$

\section{CARDIAC INVOLVEMENT}

The prevalence of congenital cardiac diseases in patients with PHACE syndrome is $41 \%$ to $67 \%$, being coarctation of the aorta responsible for $19-30 \%$ of these cases. ${ }^{24}$ Approximately $50 \%$ of patients with cardiac involvement have an aberrant origin of the subclavian artery, with or without a vascular ring. ${ }^{25}$ The most frequent changes to the aortic arch arise in the transverse and descendent portions. An obstruction usually occurs in the long segment instead of the juxtaductal portion, which is the most affected area in patients with malformations that are unrelated to PHACE syndrome. This obstruction is characterized by a narrowing or interruption, with subsequent aneurysmatic dilatation of the adjacent segments.

In patients with PHACE syndrome, $37 \%$ of cases with aortic arch anomalies will need surgical intervention. Nonsurgical cases should be followed with an annual echocardiogram due to the possibility of lesion progression. ${ }^{3}$ 


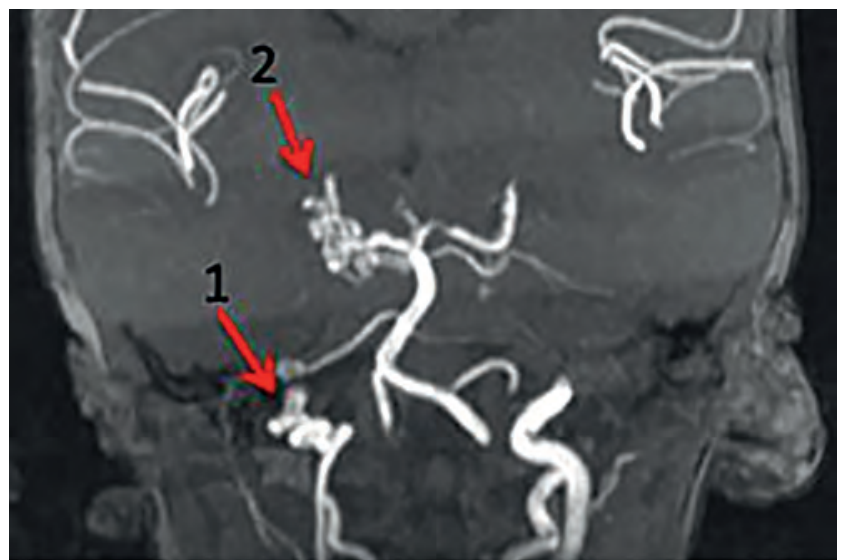

FIGURE 6: MRA showing stenosis and tortuous 1. right internal carotid artery and 2. right posterior cerebral artery

\section{OTHER INVOLVEMENT}

During the follow-up of PHACE syndrome patients, new comorbidities can be detected, such as headaches and endocrine, auditory, and dental changes. ${ }^{3}$

Headaches are more frequent and intense and begin at an early age. In these cases, a neurological assessment and an investigation of vasculopathy and cerebral ischemia should be performed using imaging tests, even in the absence of cerebrovascular changes on the initial MRI.

Auditory deficiency and speech delay are common findings. Delayed language can be due to an auditory deficit from neurosensory involvement when the IH affects cranial nerve VIII (vestibulocochlear). In these cases, the diagnosis should be made as early as possible to ensure therapeutic success and avoid sequelae. All patients with PHACE syndrome should be assessed in the neonatal period and, if they have a high risk for auditory deficiency, undergo an annual audiological evaluation. ${ }^{26}$

Certain patients with PHACE syndrome can present with dysphagia, feeding difficulties, and speech delays. ${ }^{27}$ These changes are usually observed in patients with posterior fossa malformations; lip, oropharyngeal, and airway IHs; and previous cardiac surgery. Dysphagia can be secondary to the location of the IH (lips, oral cavity, and pharynx) or to motor coordination. Speech delays that are detected early should be followed by an otorhinolaryngologist; an approach with timely speech therapy will determine its progress. $^{3,26}$

Endocrine abnormalities have been described in PHACE syndrome, such as thyroid dysfunction, hypopituitarism with growth hormone deficiency, and adrenal insufficiency. ${ }^{28}$ Hypothyroidism can be caused by changes in the hypothalamus, pituitary gland, or thyroid, which can be ectopic or malformed. ${ }^{29}$

Neonatal hypoglycemia can be a sign of hypopituitarism and warrants endocrine screening. Other effects of pituitary dysfunction include hypogonadotropic hypogonadism, which manifests as delayed puberty and adrenal insufficiency. ${ }^{28}$

Dental abnormalities, including enamel hypoplasia, which increases the risk of cavities, have also been described. They are more

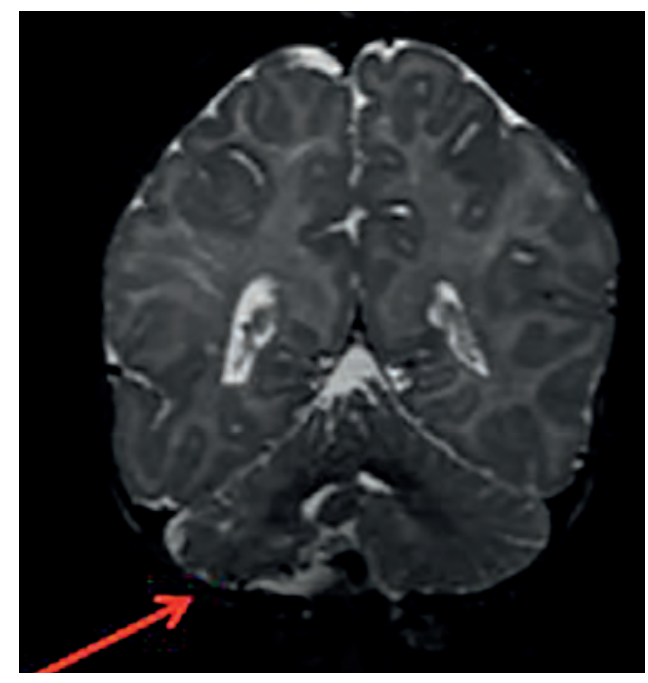

FigURE 7: Brain MRI showing hypoplasia of the right cerebellum frequent when the hemangioma is located in the oral cavity, and dental follow-up is recommended starting in the first year of life. ${ }^{30,31}$

\section{DIAGNOSTIC SCREENING}

In cases of suspected PHACE syndrome, the initial physical examination should include an assessment for ocular and sternal midline abnormalities, in addition to neurological and cardiac evaluations. An echocardiogram should always be performed, and if there are any abnormal findings, cardiac MRI and MRA are indicated to better examine the heart and brachiocephalic anatomy. Gadolinium MRI and MRA of the brain, neck, and aortic arch should be performed in the diagnostic screen for all suspected cases of PHACE syndrome. MRI is insufficient to detect all arterial abnormalities, necessitating an MRA. 2,3,8,32

There is no consensus regarding the frequency with which imaging should be performed. In certain institutions, especially for high-risk cases, the tests are performed every 3 months, whereas others conduct them annually. Each case must be considered individually according to its abnormalities and associated symptoms.

The indications for such tests must be carefully evaluated due to exposure to the anesthetic and contrast agent. Several services have adopted the restraining technique to avoid sedation and anesthesia. ${ }^{3}$

\section{INFANTILE HEMANGIOMA TREATMENT}

Propranolol is the preferred medication for IH when systemic treatment is indicated..$^{33}$ The safe use of propranolol in patients with PHACE syndrome is based on a careful examination of potential extracutaneous anomalies that are associated with the $\mathrm{IH}$, and the therapeutic choice depends on the recommendations of a multidisciplinary team.

There are several controversies regarding the use of propranolol in PHACE syndrome patients who have arterial disease due to the risk of CVA. However, the few CVA cases in the literature had severe arteriopathies. ${ }^{8,19}$

In PHACE syndrome, propranolol use should be considered carefully due the risk of lowered flow and cerebrovascular 
accidents, especially when there are CNS arterial anomalies, such as narrowing or lack of visualization of the principal cerebral or cervical arteries, associated with cardiac and aortic arch anomalies. ${ }^{20}$

The medication can be initiated in the outpatient setting, limiting hospitalization to children aged under 8 weeks who have cardiovascular and respiratory comorbidities. The optimal dose is achieved slowly to minimize sudden changes in blood pressure. The initial dose is 0.5 to $1 \mathrm{mg} / \mathrm{kg} /$ day in the first week, increasing progressively to 2 to $3 \mathrm{mg} / \mathrm{kg} /$ day b.i.d. or t.i.d. The medication should be preferably administered during the day, followed immediately by food. Propranolol should be discontinued if upper airway infections develop with bronchospasm and in situations of reduced food intake. ${ }^{20}$

Metry et al. reported 32 cases of children with PHACE syndrome who were treated with oral propranolol, 7 of whom were at high risk for CVA, based on the MRA, and in whom the syndrome was associated with cardiovascular abnormalities. Of the patients who were being followed, one presented with hemiparesis; in this case, treatment with propranolol was maintained, and there was recovery from motor deficits. The authors concluded that the risk for CVA in these patients is related to several factors, including arterial stenosis, abnormalities of the circle of Willis, the degree of collateral circulation, and the coexistence of cardiac and aortic arch anomalies that can lead to thromboembolic events. ${ }^{20}$

Although the resolution of $\mathrm{IH}$ is well documented during treatment with oral propranolol, several authors have reported the possibility of recurrence and tumor growth on discontinuation. ${ }^{34} \mathrm{We}$ believe that in these cases, the medication was halted prematurely - in the proliferative phase and especially for deep and segmental IHs. We conclude that the treatment duration will depend on the intrinsic features and clinical progression of each IH. Thus, the treatment should be discontinued when there is no further reduction in the lesion while on the medication. ${ }^{35,36}$ It is necessary to follow the patient after he stops taking propranolol, and in cases of recurrence, the medication can be restarted.

\section{OUTCOME AND PROGNOSIS}

Recent studies have detailed the features of PHACE syndrome, but the long-term outcomes for such patients are poorly described. Brain and cervical vascular anomalies are observed in most cases, but there are no reports on the clinical outcomes of these changes after propranolol use.

The most common extracutaneous involvement is structural and vascular in the brain. Thus, neurological and cognitive impairments are potential causes of morbidity in these patients. ${ }^{2}$

A multidisciplinary assessment that identifies possible CNS, cardiac, ocular, hormonal, auditory, language, and swallowing abnormalities in a timely manner allows effective interventions to be implemented to prevent future complications. $\square$

\section{REFERENCES}

1. Kilcline C, Frieden IJ. Infantile hemangiomas: how common are they? A systematic review of the medical literature. Pediatr Dermatol. 2008;25:168-73.

2. Hess CP, Fullerton HJ, Metry DW, Drolet BA, Siegel DH, Auguste KI, et al. Cervical and intracranial arterial anomalies in 70 patients with PHACE syndrome. AJNR Am J Neuroradiol. 2010;31:1980-6.

3. Garzon MC, Epstein LG, Heyer GL, Frommelt PC, Orbach DB, Baylis AL, et al PHACE Syndrome: Consensus-Derived Diagnosis and Care Recommendations. J Pediatr. 2016;178:24-33.e2.

4. Bracken J, Robinson I, Snow A, Watson R, Irvine AD, Rea D, et al. PHACE syndrome: MRI of intracerebral vascular anomalies and clinical findings in a series of 12 patients. Pediatr Radiol. 2011:41:1129-38

5. Pascual-Castroviejo I. Vascular and nonvascular intracranial malformation associated with external capillary hemangiomas. Neuroradiology. 1978;16:82-4.

6. Frieden IJ, Reese V, Cohen D. PHACE syndrome. The association of posterior fossa brain malformations, hemangiomas, arterial anomalies, coarctation of the aorta and cardiac defects, and eye abnormalities. Arch Dermatol. 1996;132:307-11.

7. Metry DW, Dowd CF, Barkovich AJ, Frieden IJ. The many faces of PHACE syndrome. J Pediatr. 2001;139:117-23.

8. Metry D, Heyer G, Hess C, Garzon M, Haggstrom A, Frommelt P, et al. Consensus Statement on Diagnostic Criteria for PHACE Syndrome. Pediatrics. 2009;124:1447-56.

9. Metry DW, Haggstrom AN, Drolet BA, Baselga E, Chamlin S, Garzon M, et al. A prospective study of PHACE syndrome in infantile hemangiomas: demographic features, clinical findings, and complications. Am J Med Genet A. 2006;140:975-86.

10. Chiller KG, Passaro D, Frieden IJ. Hemangiomas of infancy: clinical characteristics, morphologic subtypes, and their relationship to race, ethnicity, and sex. Arch Dermatol. 2002;138:1567-76.

11. Haggstrom AN, Lammer EJ, Schneider RA, Marcucio R, Frieden IJ. Patterns of infantile hemangiomas: new clues to hemangioma pathogenesis and embryonic facial development. Pediatrics. 2006;117:698-703
12. Raas-Rothschild A, Nir A, Gillis R, Rein AJ. Giant congenital aortic aneurysm with cleft sternum, supraumbilical raphé, and hemangiomatosis: report and review. Am J Med Genet. 2000;90:243-5.

13. Nina BID NZ, Machado MCMR, Macea JM. Presentation, progression and treatment of cutaneous hemangiomas - Experience of the Outpatients Clinic of Pediatric Dermatology - Hospital das Clínicas da Universidade de São Paulo. An Bras Dermatol. 2006;81:323-7.

14. Metry DW. Potential complications of segmental hemangiomas of infancy. Semin Cutan Med Surg. 2004;23:107-15.

15. Nabatian AS, Milgraum SS, Hess CP, Mancini AJ, Krol A, Frieden IJ. PHACE without face? Infantile hemangiomas of the upper body region with minimal or absent facial hemangiomas and associated structural malformations. Pediatr Dermatol. 2011:28:235-41.

16. Antonov NK, Spence-Shishido A, Marathe KS, Tlougan B, Kazim M, Sultan S, et al. Orbital Hemangioma with Intracranial Vascular Anomalies and Hemangiomas: A New Presentation of PHACE Syndrome? Pediatr Dermatol. 2015;32:e267-72.

17. Chan YC, Eichenfield LF, Malchiodi J, Friedlander SF. Small facial haemangioma and supraumbilical raphe--a forme fruste of PHACES syndrome? Br J Dermatol. 2005;153:1053-7.

18. Torer B, Gulcan H, Kilicdag H, Derbent M. PHACES syndrome with small, lateonset hemangiomas. Eur J Pediatr. 2007;166:1293-5.

19. Siegel DH, Tefft KA, Kelly T, Johnson C, Metry D, Burrows P, et al. Stroke in children with posterior fossa brain malformations, hemangiomas, arterial anomalies, coarctation of the aorta and cardiac defects, and eye abnormalities (PHACE) syndrome: a systematic review of the literature. Stroke. 2012;43:1672-4.

20. Metry D, Frieden IJ, Hess C, Siegel D, Maheshwari M, Baselga E, et al. Propranolo use in PHACE syndrome with cervical and intracranial arterial anomalies: collective experience in 32 infants. Pediatr Dermatol. 2013;30:71-89.

21. Melnick LE, Yan AC, Licht DJ, Treat JR, Castelo-Soccio L. PHACE syndrome: a retrospective review of 23 patients. Pediatr Dermatol. 2014;31:390-2.

22. Tangtiphaiboontana J, Hess CP, Bayer M, Drolet BA, Nassif LM, Metry DW, et 
al. Neurodevelopmental abnormalities in children with PHACE syndrome. J Child Neurol. 2013;28:608-14.

23. Brosig CL, Siegel DH, Haggstrom AN, Frieden IJ, Drolet BA. Neurodevelopmental Outcomes in Children with PHACE Syndrome. Pediatr Dermatol. 2016;33:415-23.

24. Haggstrom AN, Garzon MC, Baselga E, Chamlin SL, Frieden IJ, Holland K, et al. Risk for PHACE syndrome in infants with large facial hemangiomas. Pediatrics. 2010;126:e418-26

25. Bayer ML, Frommelt PC, Blei F, Breur JM, Cordisco MR, Frieden IJ,et al. Congenital cardiac, aortic arch, and vascular bed anomalies in PHACE syndrome (from the International PHACE Syndrome Registry). Am J Cardiol. 2013;112:1948-52.

26. Rudnick EF, Chen EY, Manning SC, Perkins JA. PHACES syndrome: otolaryngic considerations in recognition and management. Int J Pediatr Otorhinolaryngol. 2009:73:281-8.

27. Martin KL, Arvedson JC, Bayer ML, Drolet BA, Chun R, Siegel DH. Risk of dysphagia and speech and language delay in PHACE syndrome. Pediatr Dermatol. 2015;32:64-9.

28. Altin H, Alp H, Sap F, Karataş Z, Baysal T, Karaaslan S. PHACE syndrome with growth hormone deficiency and absence of bilateral internal carotid arteries: a case report. Pediatr Dermatol. 2012;29:316-9.

29. Goddard DS, Liang MG, Chamlin SL, Svoren BM, Spack NP, Mulliken JB.
Hypopituitarism in PHACES Association. Pediatr Dermatol. 2006;23:476-80.

30. Chiu YE, Siegel DH, Drolet BA, Hodgson BD. Tooth enamel hypoplasia in PHACE syndrome. Pediatr Dermatol. 2014;31:455-8.

31. Hartemink DA, Chiu YE, Drolet BA, Kerschner JE. PHACES syndrome: a review. Int J Pediatr Otorhinolaryngol. 2009;73:181-7.

32. Foster KA, Ares WJ, Tempel ZJ, McCormick AA, Panigrahy A, Grunwaldt LJ, Greene $S$, et al. PHACE syndrome is associated with intracranial cavernous malformations. Childs Nerv Syst. 2016;32:1463-9.

33. Drolet BA, Frommelt PC, Chamlin SL, Haggstrom A, Bauman NM, Chiu YE, et al. Initiation and use of propranolol for infantile hemangioma: report of a consensus conference. Pediatrics. 2013;131:128-40.

34. Giachetti A, Garcia-Monaco R, Sojo M, Scacchi MF, Cernadas C, Guerchicoff Lemcke $\mathrm{M}$, et al. Long-term treatment with oral propranolol reduces relapses of infantile hemangiomas. Pediatr Dermatol. 2014;31:14-20.

35. Bagazgoitia L, Hernández-Martín A, Torrelo A.. Recurrence of infantile hemangiomas treated with propranolol. Pediatr Dermatol. 2011;28:658-62.

36. Ahogo CK, Ezzedine K, Prey S, Colona V, Diallo A, Boralevi F, et al. Factors associated with the relapse of infantile haemangiomas in children treated with oral propranolol. Br J Dermatol. 2013;169:1252-6.

$\begin{array}{lll}\text { Anita Rotter } & \text { (D) ORCID } & 0000-0002-8627-2431 \\ \text { Luciana Paula Samorano } & \text { (D) ORCID } & 0000-0001-7077-8553 \\ \text { Maria Cecília Rivitti-Machado } & \text { (D) ORCID } & 0000-0003-2910-7330\end{array}$

Zilda Najjar Prado Oliveira

Bernardo Gontijo
(D) ORCID 0000-0002-8596-1999

(D) ORCID 0000-0003-1938-5986

How to cite this article: Rotter A, Samorano LP, Rivitti-Machado MC, Oliveira ZNP, Gontijo B. PHACE syndrome: clinical manifestations, diagnostic criteria, and management. An Bras Dermatol. 2018;93(3):405-11. 